\title{
Different growth rates in amoeba of genotypically related environmental and clinical Legionella pneumophila strains isolated from a thermal spa
}

\author{
M. MOLMERET ${ }^{1}$, S. JARRAUD ${ }^{1}$, J. PIERRE MORIN ${ }^{3}$, P. PERNIN ${ }^{2}$, F. FOREY ${ }^{1}$, \\ M. REYROLLE ${ }^{1}$, F. VANDENESCH ${ }^{1}$, J. ETIENNE ${ }^{1}$ AND P. FARGE ${ }^{1 *}$ \\ ${ }^{1}$ Centre National de Référence des Légionelles EA1655, Faculté de Médecine R. T. H. Laennec, \\ Rue Guillaume Paradin, 69372 Lyon Cedex 08, France \\ ${ }^{2}$ Laboratoire de Biologie Cellulaire EA 1665, Faculté de Pharmacie, 8 Avenue Rockefeller, \\ 69373 Lyon Cedex 08, France \\ ${ }^{3}$ Thermes d'Aix-les-Bains, Place Maurice Mollard, 73013 Aix-les-Bains, France
}

(Accepted 14 November 2000)

\section{SUMMARY}

Two cases of legionellosis occurring 3 years apart were acquired in the same French thermal spa and were apparently due to the same strain of Legionella pneumophila serogroup 1, as shown by genomic macrorestriction analysis. Minor differences between the two isolates were found by random amplification PCR profiling which showed an additional band with one of the isolates. Analysis of $107 \mathrm{~L}$. pneumophila strains isolated from the spa waters by genome macrorestriction failed to identify the infective strain, but a closely related $L$. pneumophila serogroup 3 strain differing from the clinical isolates by only one band was found. To determine if the clinical L. pneumophila serogroup 1 isolates was better adapted for intracellular multiplication than related serogroup 3 environmental isolates, the growth kinetics of six isolates were determined in co-culture with Acanthamoeba lenticulata. One clinical isolate failed to grow within amoeba, while the other clinical isolate yielded the highest increase in bacterial cell count per amoeba $(1200 \%)$ and the environmental isolates gave intermediate values.

Genetic analysis of L. pneumophila isolates by DNA macrorestriction does not therefore appear to reflect their growth kinetics within amoeba, and is not sufficiently discriminatory to identify potentially virulent strains.

\section{INTRODUCTION}

Legionella pneumophila [1] belongs to the Legionellaceae family, which comprises at least 43 species [2]. L. pneumophila serogroup 1 is most frequently associated with legionellosis. Legionellae are inhaled in aerosols created mainly by hot water distribution systems, cooling towers and thermal spa water [3-7]. L. pneumophila is a facultative intracellular pathogen that infects human macrophages, monocytes and epithelial cells [8-10], and in the

* Author for correspondence. aquatic environment, it can survive and multiply within amoebae, which act as natural hosts. Uptake by amoeba and survival of $L$. pneumophila is influenced by environmental conditions such as temperature [11]. Bacteria growing within amoeba are changed phenotypically and exhibit an increased resistance to antibiotics and biocides when compared with cells grown in conventional media [12-14].

In vitro co-culture models have been developed to study the interaction between amoebae and legionella, and the effects of external conditions (temperature, sunlight, etc.) on the growth of the two organisms 
$[5,15,16]$, as well as to identify several legionella genes involved in virulence. The growth kinetics of $L$. pneumophila within amoeba such as Acanthamoeba spp. [17, 18] and Hartmannella spp. [19] vary according to the bacterial strain and extrinsic factors such as the number of subcultures of the strain [20]. Strains lacking mip (macrophage infectivity potentiator gene) [21], dot (defect in organelle trafficking gene) [22], icm (intracellular multiplication gene) [23], eml (early stage macrophage-induced locus) [24], and pmi (protozoan and macrophage infectivity loci) $[25,26]$ grow more slowly than the parent strains in coculture. A study of the general stress response of $L$. pneumophila to a modified cellular environment identified the role of $r p o S$ gene [27], which regulates genes that enable its survival within the protozoa [28]. Other genes are also required for intracellular survival during the early stages of infection and include pil $B C D$, eml-early macrophage induced locus or intracellular replication (asd-aspartate semialdehyde deshydrogenase) [29]. A relationship between growth kinetics and virulence is suspected, as L. pneumophila strains with the highest growth rate in co-culture also display enhanced entry into mouse or human cells [17, $18,30,31]$.

In 1994 and 1997, L. pneumophila type 1 isolates were recovered from two patients who had developed legionellosis at the same French Alpine thermal spa. In order to determine the precise source of infection, legionella isolates from the spa waters were compared to the two clinical isolates by means of pulsed-field gel electrophoresis (PFGE) and random amplified polymorphic DNA (RAPD). The growth kinetics of the clinical and environmental legionella isolates within Acanthamoeba sp. were compared to determine whether this parameter reflected virulence in vivo.

\section{MATERIALS AND METHODS}

\section{Patient and environmental isolates}

The clinical isolates were obtained by bronchoalveolar lavage (BAL) from two patients infected during stays at the same thermal spa. Patient 1 (B.P.) was a 40year-old man with Still's disease, who was receiving $21 \mathrm{mg}$ of prednisone daily and $40 \mathrm{mg}$ of methotrexate weekly. Against medical advice, he attended the thermal spa in July 1994 for a routine 21-day thermal cure. In August 1994, 5 days after returning home, he developed severe acute pneumonia involving both lungs on the chest X-ray film. He was admitted to an

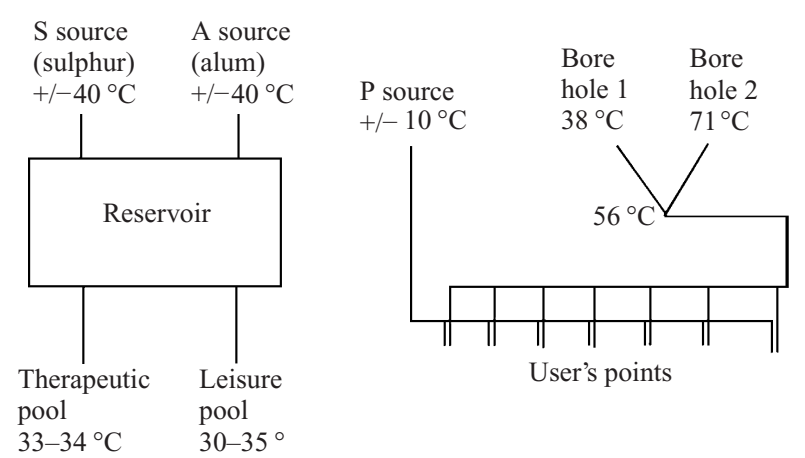

Fig. 1. Schematic diagram of the thermal spa water distribution system.

intensive care unit (ICU), where a BAL fluid sample grew L. pneumophila serogroup 1 (> $10^{5}$ c.f.u. $/ \mathrm{ml}$ ). His condition deteriorated rapidly despite appropriate antibiotic therapy and he became neutropenic $(500 \mathrm{G} / \mathrm{L})$. He died on the fourth day in ICU. The clinical strain (SC94) was stored at $-80{ }^{\circ} \mathrm{C}$.

Patient 2 (F. J.) was a 69-year-old man with chronic obstructive bronchopneumonia who attended the spa in August 1997. Fifteen days after his arrival he developed fever, cough and dyspnoea. Crackles were present and the chest X-ray film showed signs of pneumonia. He received an oral $\beta$-lactam antibiotic but his clinical status worsened and he was admitted to an ICU where he was given ofloxacin and cefotaxime, which was replaced with rovamycin when BAL fluid culture yielded L. pneumophila serogroup 1 (10 c.f.u./ml). He was cured after 20 days of antibiotic treatment. The clinical strain (SC97) was stored at $-80^{\circ} \mathrm{C}$.

To determine the source of infection, 11 water samples were collected throughout the spa's distribution system. The thermal spa receives water from three natural springs (S, sulphur; A, alum and $\mathrm{P}$, cold water) and two bore holes (Bh1 and Bh2). Water from these sources are then mixed as shown schematically in Fig. 1, and distributed throughout the buildings at temperatures optimal for the various uses. The 11 samples yielded 107 legionella strains. The environmental isolates were collected over a 2-year period following the second case of legionellosis at the thermal spa. Eighty-one strains were identified as $L$. pneumophila (27 serogroup 1, 1 serogroup 2, 62 serogroup 3, 3 serogroup 6 and 9 serogroup 13), and 26 as L. dumoffii (Table 1). Seven isolates came from source A, 6 from source $\mathrm{S}$, and 3 from source $\mathrm{P} ; 44$ isolates came from the thermal water distribution network, 13 from pools and 5 from internal reservoirs (Table 1). All strains were identified by a combination 
Table 1. PFGE types of the $\mathrm{L}$. pneumophila isolates from patients and thermal spa water

\begin{tabular}{|c|c|c|c|}
\hline Strain designation & Origin & Serogroup & PFGE type \\
\hline \multicolumn{4}{|l|}{ Clinical strains } \\
\hline SC94 & Patient 1 & 1 & $\mathrm{U}$ \\
\hline SC97 & Patient 2 & 1 & $\mathrm{U}$ \\
\hline \multicolumn{4}{|c|}{ Environmental strains } \\
\hline AX1-13 & User's point & 3 & A \\
\hline AX15-26 & User's point & 3 & A \\
\hline AX28-29 & User's point & 3 & A \\
\hline AX32 & User's point & 3 & A \\
\hline AX61 & User's point & 13 & A \\
\hline AX14 & Pool PMI & 3 & A \\
\hline $\mathrm{AX} 27$ & Pool PMI & 3 & A \\
\hline AX30-31 & Pool PMI & 3 & A \\
\hline AX34 & User's point & 3 & B \\
\hline AX33 & User's point & 3 & $\mathrm{C}$ \\
\hline AX35 & User's point & 3 & $\mathrm{D}$ \\
\hline AX36-37 & Reservoir & 3 & $\mathrm{E}$ \\
\hline AX38 & Source A & 3 & $\mathrm{~F}$ \\
\hline AX42 & Source A & 3 & $\mathrm{~F}$ \\
\hline AX40 & Source S & 3 & $\mathrm{~F}$ \\
\hline AX39 & Pool PMI & 3 & $\mathrm{~F}$ \\
\hline AX41 & Pool PMI & 3 & $\mathrm{~F}$ \\
\hline AX43 & Source S & 3 & G \\
\hline AX44 & User's point & 3 & $\mathrm{H}$ \\
\hline AX45-46 & Source A & 3 & I \\
\hline AX75-77 & User's point & 6 & $\mathrm{~J}$ \\
\hline AX72-74 & Source A & 1 & $\mathrm{~K}$ \\
\hline AX60 & Reservoir & 3 & $\mathrm{~L}$ \\
\hline AX78 & Reservoir & 2 & M \\
\hline AX55-56 & Source S & 3 & $\mathrm{~N}$ \\
\hline AX57 & User's point & 3 & $\mathrm{O}$ \\
\hline AX58-59 & Pool PMI & 3 & $\mathrm{P}$ \\
\hline AX62-68 & User's point & 13 & Q \\
\hline AX69 & User's point & 13 & $\mathrm{R}$ \\
\hline AX70 & Source S & 1 & $\mathrm{~S}$ \\
\hline AX47 & Source S & 3 & $\mathrm{~T}$ \\
\hline AX80-81 & Source P & 1 & U \\
\hline AX71 & User's point & 1 & U \\
\hline AX48-49 & Pool PMI & 3 & U \\
\hline AX51 & Pool PMI & 3 & $\mathrm{U}$ \\
\hline AX52 & User's point & 3 & $\mathrm{U}$ \\
\hline AX54 & User's point & 3 & $\mathrm{U}$ \\
\hline AX82 & Cold water & 3 & U \\
\hline AX50 & Reservoir & 3 & $\mathrm{U}$ \\
\hline AX53 & Reservoir & 3 & $\mathrm{U}$ \\
\hline
\end{tabular}

of biochemical activity [32] and direct fluorescent assay with adsorbed and unadsorbed sera [33]. The reference L. pneumophila strain ATCC 33152 was used as a control.

\section{Pulsed field gel electrophoresis (PFGE)}

Genomic DNA was prepared as previously described with some modifications [34, 35]. Briefly, legionellae were treated with proteinase $\mathrm{K}(50 \mu \mathrm{g} / \mathrm{ml})$ in $\mathrm{TE}$ buffer (10 mm Tris- $\mathrm{HCl}$ and $1 \mathrm{~mm}$ EDTA, $\mathrm{pH} 8)$ for $24 \mathrm{~h}$ at $55^{\circ} \mathrm{C}$, and DNA was digested with $20 \mathrm{IU}$ of Sfi restriction enzyme (Boehringer-Mannheim, Meylan, France) for $16 \mathrm{~h}$ at $50^{\circ} \mathrm{C}$. Fragments of DNA were separated in $0.8 \%$ agarose gel (Fast-Lane, FMC) prepared and run in $0.5 \mathrm{~mm}$ Tris-borate-EDTA 
buffer ( $\mathrm{pH} \mathrm{8.3)} \mathrm{in} \mathrm{a} \mathrm{contour-clamped} \mathrm{homogeneous}$ field apparatus (CHEF DRII system; Bio-Rad, Ivry sur Seine, France) with a constant voltage of $150 \mathrm{~V}$. Runs were carried out with constant pulse times ( $25 \mathrm{~s}$ ) at $10^{\circ} \mathrm{C}$ for $11 \mathrm{~h}$ and increasing pulse times $(35-60 \mathrm{~s})$ at $10^{\circ} \mathrm{C}$ for $11 \mathrm{~h}$. The agarose gels were stained with ethidium bromide and photographed under UV light. Band patterns were interpreted with the aid of Taxotron software (Institut Pasteur, Paris, France), based on the unweighted pair grouped with mathematical average (UPGMA) method to construct dendrograms. Isolates with patterns which differed by no more than three restriction fragments were considered to have the same pulsotype, while organisms differing by more than three restriction fragments were considered sufficiently divergent to warrant a separate pulsotype designation [36].

\section{RAPD technique}

DNA was extracted from legionellae by a thermal lysis procedure [37] followed by phenol/chloroform/ isoamyl alcohol purification and precipitation in absolute ethanol. Random amplification was performed using previously described random primers [24] (Eurogentec, Seraing, Belgium): AP8 (5'-TTGCTGGCCTAGTTAAACGTA-3') and AP9 (5'ATGCGTAACCGTAACGTGCTGACT-3'). The reaction mixture consisted of $5 \mu \mathrm{g}$ of DNA template, $4 \mathrm{~mm} \mathrm{MgCl}_{2}, 0.2 \mathrm{~mm}$ of each dNTP (Pharmacia Biotech, Uppsala, Sweden), $2.5 \mathrm{U}$ of Taq DNA polymerase (Amplitaq; Perkin-Elmer Cetus, Branchburg, N.J.), and $50 \mathrm{pmol}$ of each primer in PCR buffer (10 mm Tris- $\mathrm{HCl} \mathrm{pH} \mathrm{8.3,50} \mathrm{mm} \mathrm{KCl,}$ $0.001 \%$ gelatin; Perkin-Elmer Cetus). PCR cycles comprised a 1-min denaturation step at $94{ }^{\circ} \mathrm{C}$, followed by hybridization for $2 \mathrm{~min}$ at $30^{\circ} \mathrm{C}$ and extension at $72{ }^{\circ} \mathrm{C}$ for $1 \mathrm{~min}$ ( 40 cycles) and for $3 \mathrm{~min}$ at $72{ }^{\circ} \mathrm{C}$ (one final extension cycle). PCR products were run on standard $1.5 \%$ agarose gel (SeaKem GTG; FMC BioProducts, Rockland, Maine), stained with ethidium bromide, and photographed under UV light.

\section{Co-culture of legionella with amoebae}

Acanthamoeba lenticulata PD2, an axenized reference strain, was cultured in a $10 \% \mathrm{X}$-ray-inactivated fetal calf serum casein glucose yeast extract medium
(SCGYEM) at $30^{\circ} \mathrm{C}$. Amoebae were inoculated into $25 \mathrm{~cm}^{2}$ tissue culture flasks (Greiner laboratories, Frickenhausen, Germany) containing $14 \mathrm{ml}$ of SCGYEM liquid medium and incubated for $72 \mathrm{~h}$ at $30{ }^{\circ} \mathrm{C}$. SCGYEM medium was then replaced by the same volume of saline solution, as previously described [26]. Bacterial strains were grown on buffered charcoal yeast extract (BCYE) agar supplemented with $0.1 \% \alpha$-ketoglutarate, glycine, vancomycin and colistin (GVPC) for $72 \mathrm{~h}$. Co-culture was conducted at $30{ }^{\circ} \mathrm{C}$ in saline solution at $\mathrm{pH} 7$ in tissue culture flasks with a ratio of one bacterium per 100 amoebae. Controls included the saline solution alone, with either legionellae or amoebae. Amoebae and legionellae were both quantified after 1, 2 and 3 days. Amoebae were counted directly in the tissue culture flask, using an inverted microscope, and the whole content of a tissue culture flask was removed. Amoebae were lysed by drawing the suspension 3-5 times through a $27-$ gauge needle [16]. Legionellae (extra- and intracellular) were counted by dilution plating in triplicate on GVPC agar with incubation at $35{ }^{\circ} \mathrm{C}$ in $2.5 \% \mathrm{CO}_{2}$-air for 5-7 days. The ratio of bacterial increase versus the number of amoeba was calculated for each co-culture. Each experiment was repeated three times and standard errors were calculated from the repeated measurements.

\section{RESULTS \\ PFGE patterns of the clinical and environmental isolates}

Macrorestriction profiles of the 107 environmental and 2 clinical isolates contained 5-15 fragments ranging in size from 50 to $1000 \mathrm{~kb}$. A total of 21 pulsotypes were identified (Fig. 2), strains within a given pulsotype differing by no more than three bands [38]. Pulsotype A was the most frequent, comprising 32 environmental L. pneumophila serogroup 3 isolates. The two clinical isolates, SC94 and SC97, both belonged to pulsotype $\mathrm{U}$, as did 11 environmental isolates ( 3 serogroup 1 and 8 serogroup 3 ) originating from pools, reservoirs, the thermal water sources, and the cold water source. No profile identical to that of the clinical isolates was identified among the environmental isolates but the profile of the two clinical isolates differed by only a single band from that of five serogroup 3 environmental isolates, and were thus regarded as highly related to the latter. 


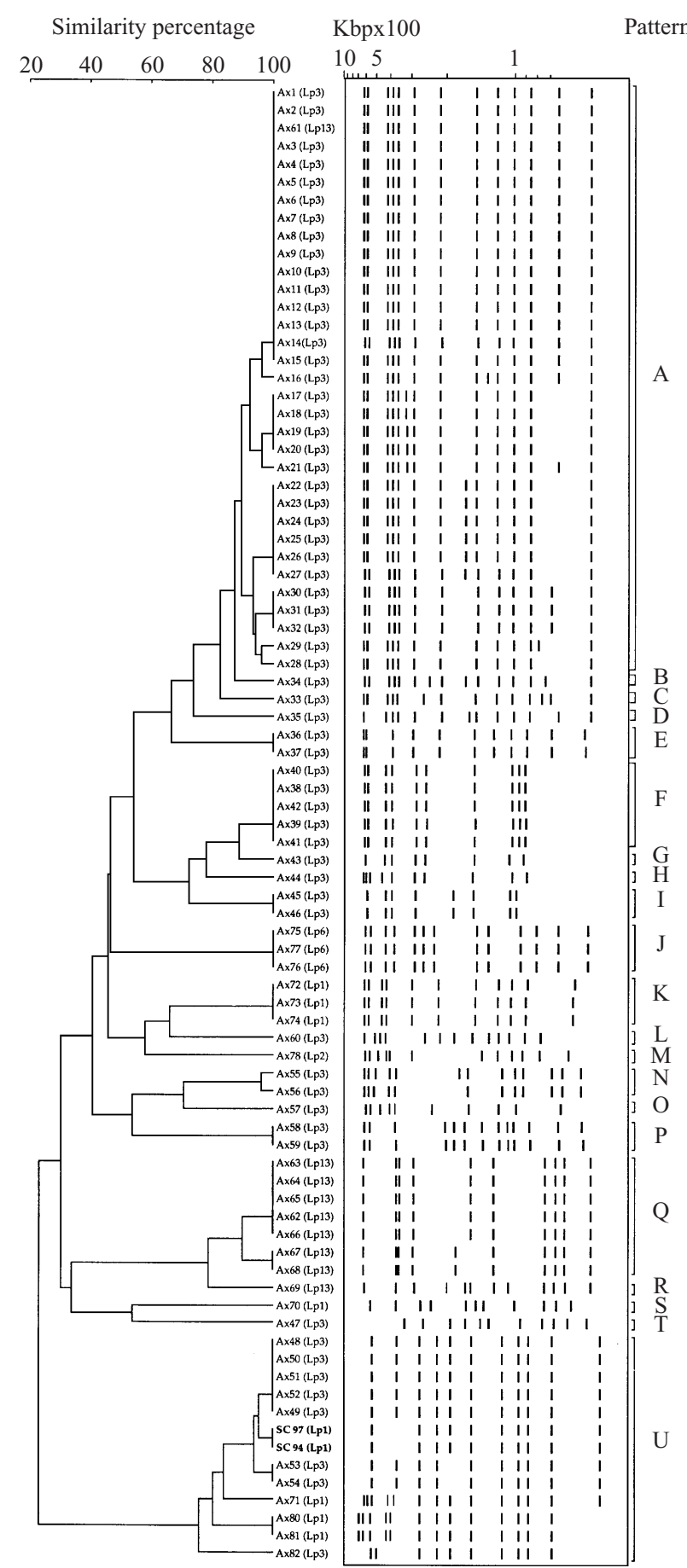

Fig. 2. Dendrogram and schematic representation of the pulsotypes of two clinical and 81 environmental isolates of Legionella pneumophila; the error threshold is $4 \%$.

\section{RAPD patterns}

To confirm the genetic relatedness of the pulsotype $\mathrm{U}$ isolates, the two clinical isolates and four representative pulsotype $\mathrm{U}$ environmental isolates were tested by RAPD. The six isolates differed from one another

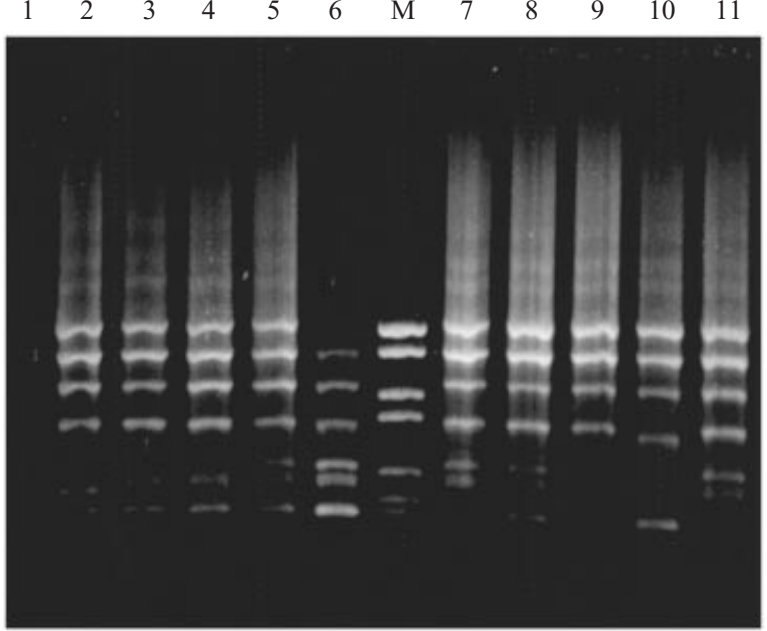

Fig. 3. RAPD patterns of clinical and selected environmental isolates from the thermal spa. Lane 1, negative control (no DNA); lanes 2 and 3, clinical isolates (SC94 and SC97); lanes 4, 8, 9 and 10, environmental isolates of serogroup $1(\mathrm{~A} \times 71, \mathrm{~A} \times 80, \mathrm{~A} \times 81$ and $\mathrm{A} \times 2)$; lanes 5,6 and 7, environmental isolates of serogroup $3(\mathrm{~A} \times 52, \mathrm{~A} \times 54$ and $\mathrm{A} \times 82)$; lane 11, L. pneumophila Philadelphia 1; lane $\mathrm{M}$, size markers.

by a maximum of one band, whereas control isolates (one pulsotype $\mathrm{A}$ isolate and the reference strain ATCC 33152) differed from the six strains by 3 or 4 bands (Fig. 2). The RAPD profiles of the two clinical isolates differed from each other by one band, while clinical isolate SC97 had a RAPD profile identical to that of environmental isolate $\mathrm{A} \times 71$ (Fig. 3, Table 2).

\section{Intra-amoebic growth rates}

The six isolates tested above by RAPD were studied for their growth kinetics in culture with Acanthamoeba lenticulata. Values differed considerably among the isolates (Fig. 4, Table 2). Interestingly, clinical isolate SC94 showed a $1200 \%$ increase in cell count per amoeba, whereas clinical isolate SC97 failed to replicate. Values for the environmental and control isolates were intermediate between those of the two clinical isolates (Table 2). None of the legionella isolates grew in saline alone. Ranking of the isolates according to their intra-amoebic multiplication rate did not reveal the ascendancy of one of the two serogroups and did not correlate with the RAPD patterns (Table 2). For a selected number of cases, coculture experiments were also performed in the presence of gentamicin to remove extracellular 
Table 2. Characteristics of clinical strains and closely related environmental strains of $\mathrm{L}$. pneumophila

\begin{tabular}{lcll}
\hline \hline Strain designation & $\begin{array}{l}\text { Bacterial increase } \\
\text { per amoeba (\%) }\end{array}$ & PFGE type & RAPD type \\
\hline Clinical strains & & & \\
L. pneumophila serogroup 1 SC94 & $1200 \cdot 84$ & $\mathrm{U}$ & $\mathrm{A}$ \\
L. pneumophila serogroup 1 SC97 & $-1 \cdot 10$ & $\mathrm{U}$ & $\mathrm{B}$ \\
Environmental strains & & $\mathrm{U}$ & $\mathrm{C}$ \\
L. pneumophila serogroup 3 AX54 & $357 \cdot 16$ & $\mathrm{U}$ & $\mathrm{E}$ \\
L. pneumophila serogroup 3 AX82 & $103 \cdot 18$ & $\mathrm{U}$ & $\mathrm{B}$ \\
L. pneumophila serogroup 1 AX71 & $80 \cdot 23$ & $\mathrm{~A}$ & $\mathrm{D}$ \\
L. pneumophila serogroup 3 AX2 & $21 \cdot 90$ & $\mathrm{U}$ & $\mathrm{C}$ \\
L. pneumophila serogroup 3 AX52 & $17 \cdot 82$ & & $\mathrm{E}$ \\
Reference strain & $11 \cdot 26$ & - & \\
L. pneumophila serogroup 1 & & & \\
reference strain ATCC 33152 & & & \\
\hline \hline
\end{tabular}

legionellae. The absolute number of countable bacteria was always lower but the kinetics of growth were similar to those obtained without antibiotics (not shown).

\section{DISCUSSION}

Despite the broad range of legionella strains recovered from the water system of this thermal spa, in terms of the number of species and pulsotypes, molecular methods (PFGE and RAPD) suggested that a single strain of L. pneumophila serogroup 1 (i.e. a clone) caused two cases of legionellosis that occurred 3 years apart. However, none of the environmental isolates had a pulsotype identical to that of the clinical isolates, and the most closely related profiles were those of several serogroup 3 environmental isolates. This suggested that the serogroup 1 clinical strain may have been derived from a serogroup 3 environmental isolate with a related pulsotype. Indeed, Harrisson et al. reported that genotypically related strains of $L$. pneumophila could express different serogroup-specific antigens $[39,40]$. Other legionella attributes, such as expression of the flagellum, are also modulated by environmental factors [41].

The presence of L. pneumophila serogroup 3 along with $L$. pneumophila serogroup 1 and $L$. dumoffii in this thermal spa had been reported in 1988 [6]; unfortunately, these environmental strains were no longer available for this study. More than 10 years later, and despite cleaning programmes and renovation of the water distribution system, the present study shows a very similar species and serogroup distribution. It should be noted that the use of chlorine is not allowed in French thermal spas in order to preserve the characteristics of the mineral water. Long-term persistence (for up to 10 years) of the same L. pneumophila serogroup 6 strain in a hospital water distribution system, and its association with sporadic cases of infection, has been reported [42, 43].

The predominance of serogroup 3 in the water distribution system of this thermal spa, and the involvement of a serogroup 1 strain in the only two cases of legionellosis reported, suggest that the serogroup 1 antigen is better adapted to human infection, while the serogroup 3 antigen may be better adapted to the aquatic environment. Acanthamoeba, which is an appropriate model for intracellular multiplication of legionella in mammalian cells [17], was thus used to study the growth of the clinical isolates and closely related environmental isolates of L. pneumophila, and its relationship with human virulence. We observed considerable variations in growth rates, even between isolates from the same serogroup (Table 2). Furthermore, the isolate recovered from the patient who died grew rapidly in amoebae, although a differential uptake capacity could play a role, while the other, isolated from the patient who survived, failed to grow at all. Co-culture with macrophages might have given different results. Although patient 1 and 2 had different underlying health problems, our results show that macrorestriction analysis is unable to distinguish between strains with high and low virulence in humans. RAPD, which is an additional discriminatory method to PFGE [42-45], showed that the two clinical strains 

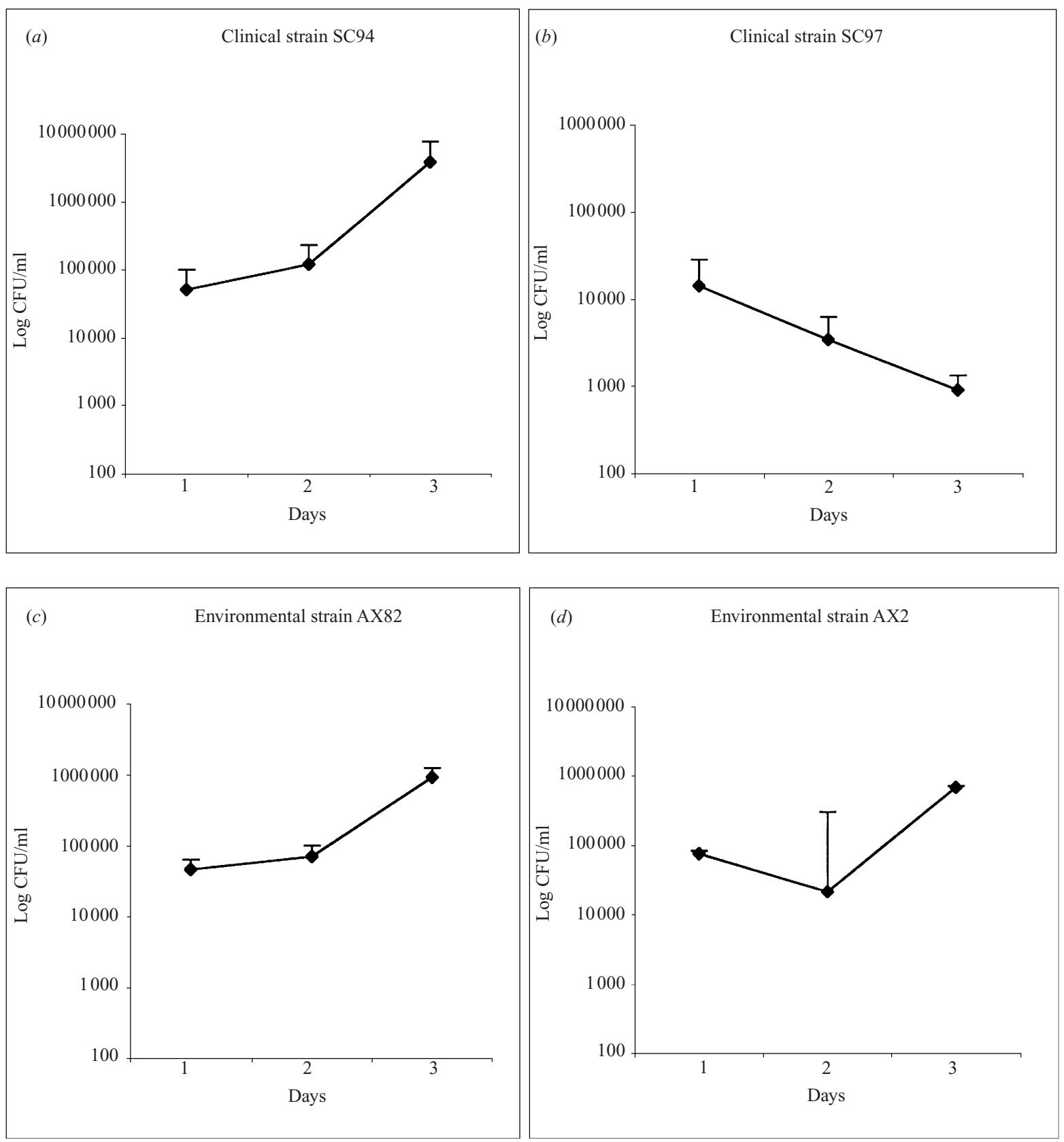

Fig. 4. Growth kinetics of clinical and selected environmental isolates in acanthamoeba. Panel (a), clinical strain SC94; Panel (b), clinical strain SC97; Panel (c), environmental isolate of serogroup 1 (AX82); Panel (d), environmental isolate of serogroup 1 (AX2). Results are given in $\log$ c.f.u./ml, with mean type errors.

differed by only one band, possibly corresponding to a genomic domain involved in virulence. Cloning and sequencing of this $0.6 \mathrm{~kb}$ RAPD fragment revealed at least one significant 124 -amino-acid open reading frame with homology with Thiosphaera pantotropha nitrite reductase [identities $=12 / 49(24 \%)$, positives $=25 / 49 \quad(50 \%)] \quad(h t t p: / / w w w . n c b i . n l m . n i h . g o v /$ BLAST/) (data not shown). This potential gene will now be expressed in legionella hosts to test its effect in the amoebic co-culture model.

\section{ACKNOWLEDGEMENTS}

This work was supported by an INSERM grant (EN98-12, programme Evironnement et Santé).

\section{REFERENCES}

1. Brenner DJ, Steigerwalt AG, McDade JE. Classification of the Legionnaires' disease bacterium: Legionella pneumophila, genus novum, species nova, of the family Legionellaceae, family nova. Ann Intern Med 1979; 90 : 656-8. 
2. Benson RF, Fields BS. Classification of the genus Legionella. Semin Resp Infect 1998; 13: 90-9.

3. Breiman RF, Fields BS, Sanden GN, et al. Association of shower use with Legionnaires' disease. JAMA 1990; 263: 2924-6.

4. Cabanes PA, Dubrou S, Larguier M, Saude I, Festy B. Les Legionella dans l'environnement hydrique sanitaire: données préliminaires pour une évaluation du risque en France. Méd Mal Infect 1995; 25: 850-7.

5. Fields BS, Sanden GN, Barbaree JM, et al. Intracellular multiplication of Legionella pneumophila in amoebae isolated from hospital hot water tanks. Curr Microbiol 1989; 18: 131-7.

6. Bornstein N, Marmet D, Surgot M, et al. Exposure to Legionellaceae at a hot spring spa: a prospective clinical and serological study. Epidemiol Infect 1989; 102: 31-6.

7. Wadowsky RM, Wilson TM, Kapp NJ, et al. Multiplication of Legionella spp. in tap water containing Hartmannella vermiformis. Appl Environ Microbiol 1991; 57: 1950-5.

8. Pearlman E, Jiwa AH, Engleberg NC, Eisenstein BI. Growth of Legionella pneumophila in human macrophage-like (U937) cell line. Microb Pathog 1988; 5: 87-95.

9. Mody CH, III RP, Shahrabadi MS, et al. Legionella pneumophila replicates within rat alveolar epithelial cells. J Infect Dis 1993; 167: 1138-45.

10. Horwitz MA. Formation of a novel phagosome by the legionnaires' disease bacterium (Legionella pneumophila) in human monocytes. J Exp Med 1983; 158: 1319-31.

11. Anand CM, Skinner AR, Malic A, Kurtz JB. Interaction of $L$. pneumophila and free living amoeba (Acanthamoeba palestiniensis). J Hyg 1983; 91 : 167-78.

12. Barker J, Brown MRW, Collier PJ, Farrell I, Gilbert P. Relationship between Legionella pneumophila and Acanthamoeba polyphaga: physiological status and susceptibility to chemical inactivation. Appl Environ Microbiol 1992; 58: 2420-5.

13. Kilvington S, Price J. Survival of Legionella pneumophila within cysts of Acanthamoeba polyphaga following chlorine exposure. J Appl Bacteriol 1990; 68: 519-25.

14. Kuchta JM, Navratil JS, Shepherd ME, et al. Impact of chlorine and heat on the survival of Hartmannella vermiformis and subsequent growth of Legionella pneumophila. Appl Environ Microbiol 1993; 59: 4096-100.

15. Dutka BJ. Sensitivity of Legionella pneumophila to sunlight in fresh and marine waters. Appl Environ Microbiol 1984; 48: 970-4.

16. Moffat JF, Tompkins LS. A quantitative model of intracellular growth of Legionella pneumophila in Acanthamoeba castellanii. Infect Immun 1992; 60: 296-301.

17. Cirillo JD, Cirillo SLG, Yan L, et al. Intracellular growth in Acanthamoeba castellanii affects monocyte entry mechanisms and enhances virulence of Legionella pneumophila. Infect Immun 1999; 67: 4427-34.
18. Vandenesch F, Surgot M, Bornstein N, et al. Relationship between free amoeba and Legionella: studies in vitro and in vivo. Zbl Bakt 1990; 272: 265-75.

19. Brieland JK, Fantone JC, Remick DG, et al. The role of Legionella pneumophila-infected Hartmannella vermiformis as an infectious particle in a murine model of Legionnaires' disease. Infect Immun 1997; 65: 5330-3.

20. Wadowsky RM, Fleisher A, Kapp NJ, et al. Multiplication of virulent and avirulent strains of Legionella pneumophila in cultures of Hartmannella vermiformis. In: Barbaree JM, Breiman RF, Dufour AP, eds. Legionella: current status and emerging perspectives. Washington, DC: American Society for Microbiology, 1993: 145-7.

21. Cianciotto NP, Eisenstein BI, Mody $\mathrm{CH}$, Engleberg NC. A mutation in the mip gene results in an attenuation of Legionella pneumophila virulence. J Infect Dis 1990; 162: 121-6.

22. Berger $\mathrm{KH}$, Isberg RR. Two distinct defects in intracellular growth complemented by a single genetic locus in Legionella pneumophila. Mol Microbiol 1993; 7: 7-19.

23. Marra A, Blander SJ, Horwitz MA, Shuman HA. Identification of a Legionella pneumophila locus required for intracellular multiplication in human macrophages. Proc Natl Acad Sci USA 1992; 89: 9607-11.

24. Abu Kwaik Y, Pederson LL. The use of differential display-PCR to isolate and characterize a Legionella pneumophila locus induced during the intracellular infection of macrophages. Mol Microbiol 1996; 21 : 543-56.

25. Gao L-Y, Harb OS, Abu Kwaik Y. Utilization of similar mechanisms by Legionella pneumophila to parasitize two evolutionarily distant host cells, mammalian macrophages and protozoa. Infect Immun 1997; 65: 4738-46.

26. Doyle RM, Steele TW, McLennan AM, et al. Sequence analysis of the mip gene of the soilborne pathogen Legionella longbeachae. Infect Immun 1998; 66: 1492-9.

27. Brown MR, Barker J. Unexplored reservoirs of pathogenic bacteria: protozoa and biofilms. Trends Microbiol 1999; 7: 46-50.

28. Hales LM, Shuman HA. The Legionella pneumophila rpoS gene is required for growth within Acanthamoeba castellanii. J Bacteriol 1999; 181: 4879-89.

29. Harb OS, Gao LY, Abu Kwaik Y. From protozoa to mammalian cells: a new paradigm in the life cycle of intracellular bacterial pathogens. Environ Microbiol 2000; 2: 251-65.

30. Brieland $\mathrm{J}$, McClain M, Heath L, et al. Coinoculation with Hartmannella vermiformis enhances replicative Legionella pneumophila lung infection in a murine model of Legionnaires' disease. Infect Immun 1996; 64: 2449-56.

31. Brieland J, McClain M, LeGendre M, Engleberg C. Intrapulmonary Hartmannella vermiformis: a potential niche for Legionella pneumophila replication in a murine model of legionellosis. Infect Immun 1997; 65: 4892-6. 
32. Harrison TG, Taylor AG. Phenotypic characteristics of Legionellae. In: Harrison TG and Taylor AG, eds. A laboratory manual for Legionella. Chichester: John Wiley \& Sons Ltd., 1988: 45-56.

33. Harrison TG, Taylor AG. Identification of Legionellae by serological methods. In: Harrison TG and Taylor AG, eds. A laboratory manual for Legionella. Chichester: John Wiley \& Sons Ltd., 1988: 57-68.

34. Grothues D, Tümmler B. Genome analysis of Pseudomonas aeruginosa by field inversion gel electrophoresis. FEMS Microbiol Lett 1987; 48: 419-22.

35. Riffard S, Lo Presti F, Vandenesch F, et al. Comparative analysis of infrequent-restriction-site PCR and pulsed-field gel electrophoresis for epidemiological typing of Legionella pneumophila serogroup 1 strains. J Clin Microbiol 1998; 36: 161-7.

36. Tenover FC, Arbeit RD, Goering RV. How to select and interpret molecular strain typing methods for epidemiological studies of bacterial infections: a review for healthcare epidemiologists. Infect Cont Hosp Epidem 1997; 18: 426-39.

37. Jaulhac B, Nowicki M, Bornstein N, et al. Detection of Legionella spp. in bronchoalveolar lavage fluids by DNA amplification. J Clin Microbiol 1992; 30: 920-4.

38. Tenover FC, Arbeit RD, Goering RV, et al. Interpreting chromosomal DNA restriction patterns produced by pulsed-field gel electrophoresis: criteria for bacterial strain typing. J Clin Microbiol 1995; 33: 2233-9.

39. Harrison TG, Saunders NA, Haththotuwa A, et al. Phenotypic variation amongst genotypically homo- geneous Legionella pneumophila serogroup 1 isolates: implications for the investigation of outbreaks of Legionnaires' disease. Epidemiol Infect 1990; 104: 171-80.

40. Harrison TG, Saunders NA, Haththotuwa A, Doshi N, Taylor AG. Further evidence that genotypically closely related strains of Legionella pneumophila can express different serogroup specific antigens. J Med Microbiol 1992; 37: 155-61.

41. Heuner K, Brand BC, Hacker J. The expression of the flagellum of Legionella pneumophila is modulated by different environmental factors. FEMS Microbiol Lett 1999; 175: 69-77.

42. Lawrence C, Reyrolle M, Dubrou S, et al. Single clonal origin of a high proportion of Legionella pneumophila serogroup 1 isolates from patients and the environment in the area of Paris, France, over a 10 -year period. J Clin Microbiol 1999; 37: 2652-5.

43. Visca P, Goldoni P, Lück PC, et al. Multiple types of Legionella pneumophila serogroup 6 in a hospital heated-water system associated with sporadic infections. J Clin Microbiol 1999; 37: 2189-96.

44. Pruckler JM, Mermel LA, Benson RF, et al. Comparison of Legionella pneumophila isolates by arbitrarily primed PCR and pulsed-field gel electrophoresis: analysis from seven epidemic investigations. J Clin Microbiol 1995; 33: 2872-5.

45. Maes N, Wauters G, Struelens MJ. Evaluation of arbitrarily primed polymerase chain reaction analysis for typing Legionella pneumophila. Clin Microbiol Infect $1998 ; 4: 149-54$. 